\title{
CLASSICAL PHOTOGRAMMETRY AND UAV - SELECTED ASCPECTS
}

\author{
S. Mikrut \\ Dept. of Geoinformation, Photogrammetry and Environmental Remote Sensing, AGH University of Science and Technology, \\ 30 Al. Mickiewicza, Cracow, Poland - smikrut@agh.edu.pl
}

Commission I, ICWG I/5b

KEY WORDS: UAV, classical (airborne) photogrammetry, geometry and radiometry aspects

\begin{abstract}
:
The UAV technology seems to be highly future-oriented due to its low costs as compared to traditional aerial images taken from classical photogrammetry aircrafts. The AGH University of Science and Technology in Cracow - Department of Geoinformation, Photogrammetry and Environmental Remote Sensing focuses mainly on geometry and radiometry of recorded images. Various scientific research centres all over the world have been conducting the relevant research for years. The paper presents selected aspects of processing digital images made with the UAV technology. It provides on a practical example a comparison between a digital image taken from an airborne (classical) height, and the one made from an UAV level. In his research the author of the paper is trying to find an answer to the question: to what extent does the UAV technology diverge today from classical photogrammetry, and what are the advantages and disadvantages of both methods? The flight plan was made over the Tokarnia Village Museum (more than $0.5 \mathrm{~km}^{2}$ ) for two separate flights: the first was made by an UAV - System FT-03A built by FlyTech Solution Ltd. The second was made with the use of a classical photogrammetric Cesna aircraft furnished with an airborne photogrammetric camera (Ultra Cam Eagle). Both sets of photographs were taken with pixel size of about $3 \mathrm{~cm}$, in order to have reliable data allowing for both systems to be compared. The project has made aerotriangulation independently for the two flights. The DTM was generated automatically, and the last step was the generation of an orthophoto. The geometry of images was checked under the process of aerotriangulation. To compare the accuracy of these two flights, control and check points were used. RMSE were calculated. The radiometry was checked by a visual method and using the author's own algorithm for feature extraction (to define edges with subpixel accuracy). After initial pre-processing of data, the images were put together, and shown side by side. Buildings and strips on the road were selected from whole data for the comparison of edges and details. The details on UAV images were not worse than those on classical photogrammetric ones. One might suppose that geometrically they also were correct. The results of aerotriangulation prove these facts, too. Final results from aerotriangulation were on the level of RMS $=1$ pixel (about $3 \mathrm{~cm})$. In general it can be said that photographs from UAVs are not worse than classic ones. In the author's opinion, geometric and radiometric qualities are at a similar level for this kind of area (a small village). This is a very significant result as regards mapping. It means that UAV data can be used in mapping production.
\end{abstract}

\section{INTRODUCTION}

The UAV technology has been known for more than 100 years, yet not always in a positive sense. During World War II unmanned flying platforms carried explosive charges (unmanned V-1 and V-2 rockets). That technique was also used by American troops during their military operations in Vietnam (UAV Ryan 147 used to gather battlefield information). In fact, as statistics prove, U.S. is the country definitely investing the most in that type of technology.

A wider development of UAVs for mapping purposes and first tests date back to the 1970s. In the beginning of the $21 \mathrm{st}$ century practically the majority of countries that have something to say in photogrammetry had already scientific and research units that worked on that technology (Eienbeiss at. all, 2004). The same can be said about Poland (Sawicki, 2012).

\section{RELATED WORK}

\subsection{UAV in Poland}

Constructing the UAV system in Poland has also its history. In 2007 Dr. Bogdan Jankowicz (presently the University of Agriculture in Cracow, Poland) conducted research on an unmanned motor hang-glider, furnished with a Vivitar camera. Results of his research were presented in his postdoctoral thesis. Research works were also conducted by Mr. Bogdan
Szczechowski from the Technical University of Gdańsk, Poland, in cooperation with Microsystems company (Szczechowski, 2008). The research outcomes included developing a technology of producing orthophotomaps from a drone and, finally, implementing several practical projects. More information on UAV technology can also be found in paper (Mikrut at all, 2013).

Also at Warsaw University of Life Sciences (SGGW), a Ph.D. student Anna Zmarz defended her doctoral thesis, where she utilized the UAV technique to make images and to analyse the condition of forests.

The technology of unmanned systems has also found commercial applications. Several Polish companies, such as OPEGIEKA from Elbląg, EUROSYSTEM from Chorzów, TAXUS SI from Warsaw, or Fotomapy from Grodzisk Dolny have invested in that technology. The last of those companies developed its own solution (the "Pteryx" drone). This vehicle can make up to $10 \mathrm{~km}^{2}$ of a map during a single flight.

TAXUS SI for more than four years have been building their own UAV, named AVI-1, exhibited later at the INTERGEO fair in 2011. AGH University of Science and Technology in Cracow has also It is also your experience - Figure 1 (Mikrut at all, 2013).

A separate issue is that of legal regulations. In the case of unmanned flights, these are the system parameters that have quite an essential importance: if an aerial vehicle weights more 
than $30 \mathrm{~kg}$, its operator must hold a special license and a permit to operate such flights. However, in the case of smaller devices, the permit is theoretically required but, at the same time, one can treat the device and its flight as an aircraft modelling hobby. Then, if the drone remains within one's view (flight altitude not exceeding $150 \mathrm{~m}$ and at least $150 \mathrm{~m}$ from urban areas) it can be used.

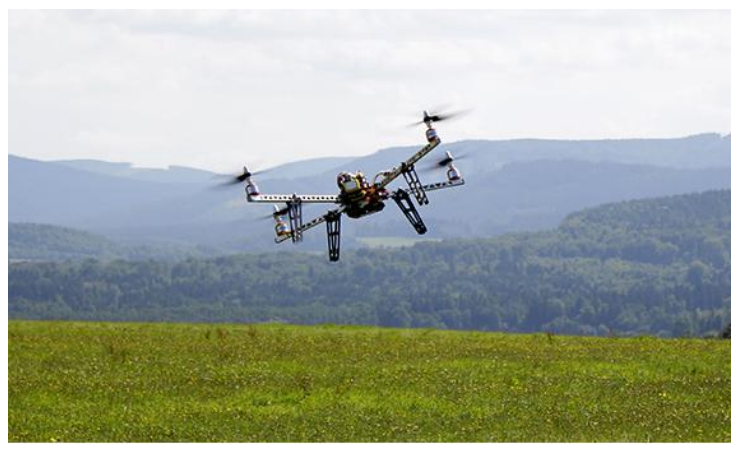

Figure 1. AGH University multirotor in operation.

\section{DATA ACQUISITION}

The author of the paper is trying in his research to find an answer to the question: to what extent does the UAV technology diverge today from classical photogrammetry, and what are the advantages and disadvantages of both methods? The paper presents examples of surveys prepared as two sets of data.

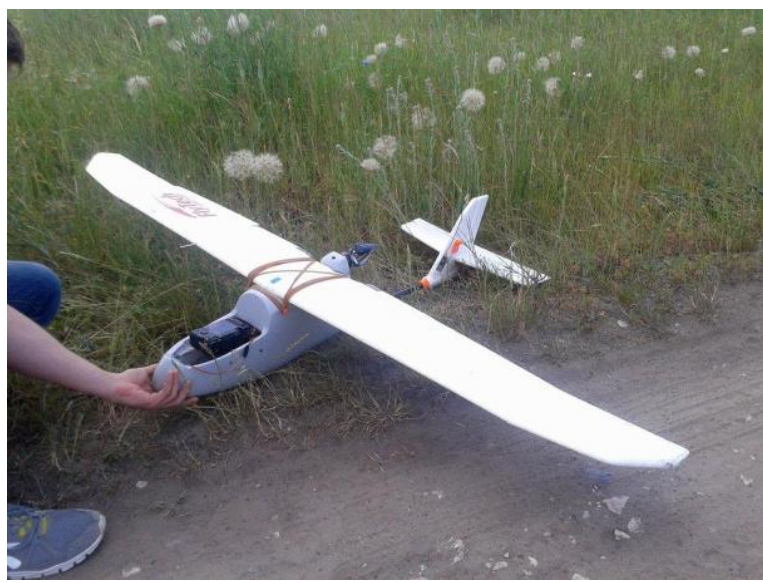

Figure 2. System FT-03A produced by FlyTEch Solutions Ltd. in Cracow as used for tests

\subsection{Two flights}

The flight plan was made over the Tokarnia Village Museum (more than $0,5 \mathrm{~km}^{2}$ ) for two separate flights: the first was made by an UAV - System FT-03A (Fig.2) built by FlyTech Solution Ltd. company from Cracow - flight plan shown in Fig.3. The second was made with the use of a classical photogrammetric Cesna aircraft furnished with a standard photogrammetric camera.

Both sets of photographs (UAV and classic) were taken with the pixel size of about $3 \mathrm{~cm}$, in order to have reliable data allowing for both systems to be compared.
Recording of images from UAV was made using a Sony NEX-7 digital camera, with resolution $6000 \times 4000$ pixels and pixel size $4 \mu \mathrm{m}$, with lens 16-55 mm (Fig.6).

Photographs of the same areas were taken from a classical photogrammetry unit (Fig.5) with a VEXCEL UltraCam EAGLE digital camera, with pixel size $5.2 \mu \mathrm{m}$ and image format $13080 \times 20010$ pixels, plus focal length of $79.80 \mathrm{~mm}$. The time difference between moments in which both photograph sets were taken was less than one month.

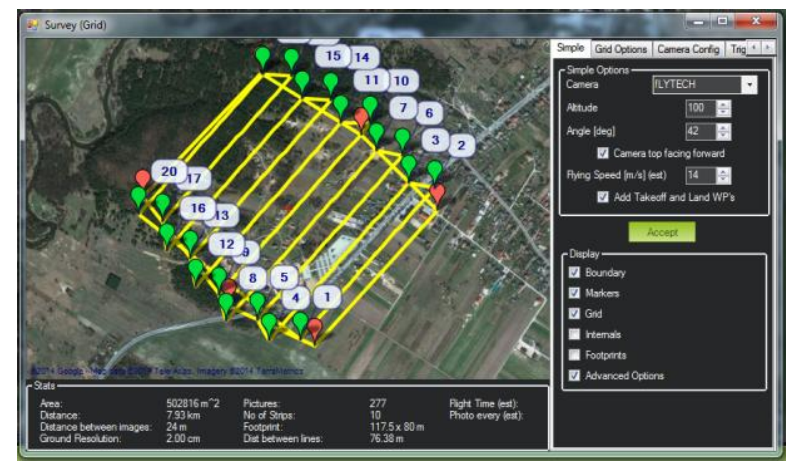

Figure 3. Flight plan made in software "Mission Planner" prepared for UAV.

Compare Figures. 3 and 6 to see the difference in the amount of photographs (for UAV images we need 10 strips, and for classical ones we need only 3 ) - table 1 .

\begin{tabular}{|l|c|c|}
\hline & classic & UAV \\
\hline Number of strips & 3 & 10 \\
\hline Number of photos & 15 & 277 \\
\hline
\end{tabular}

Table 1. Numbers of strips and photos in classic and UAV flights.

The difference between the number of pictures and strips is clearly visible to the advantage of the classic flight. However, setting the UAV is characterized by that it is carried out in an automatic process. This difference then there is of no such a great importance.

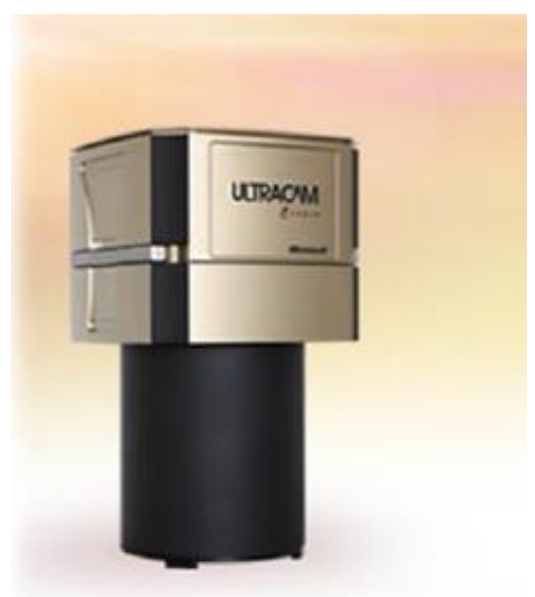

Figure 4. View of ULTRA CAM EAGLE 


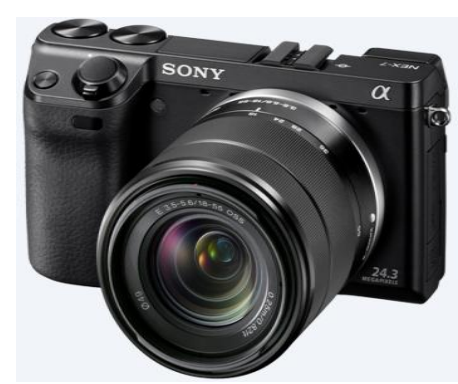

Figure 5. View of Digital Sony NEX-7, camera used in experiments

During fieldwork were also measured control and checkpoints by means of GPS technology. Distribution of the points you can see in the Fig.6 on the background of photos of classic camera Ultra Cam Eagle. Red circles denote control points and blue points denote "check points". Black points represent "tiepoints".

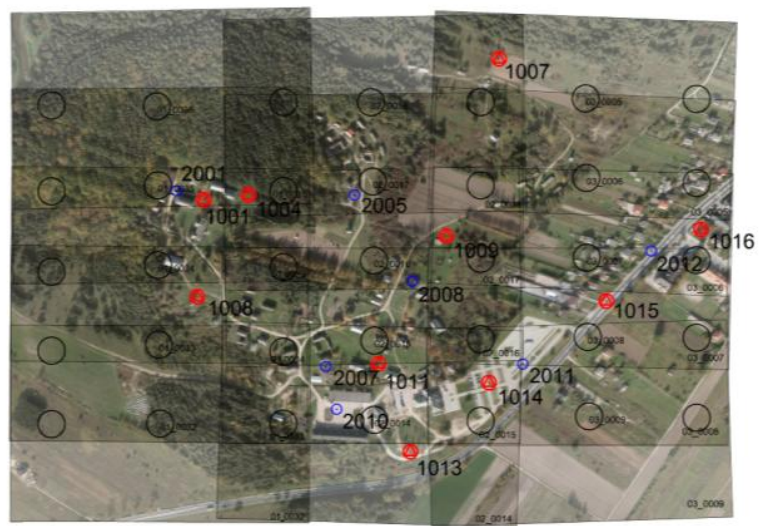

Figure 6. Digital images taken from a classical photogrammetry aircraft (only 15 images). Red circles denote "GCP" and blue points denote "check points". Black points represent "tiepoints".

The project has made aerotriangulation independent for the two flights. The DTM was generated automatically, and the last step was generation of an orthophoto with $3 \mathrm{~cm}$ pixels. The software used for test was INPHO (classic data) and AgiSoft (UAV data).

In Fig. 7 we see the ortho-generated photo with $3 \mathrm{~cm}$ pixels used for colour balancing. The area on the ortho shows the whole Tokarnia Village Museum. The point as control and check points were used.

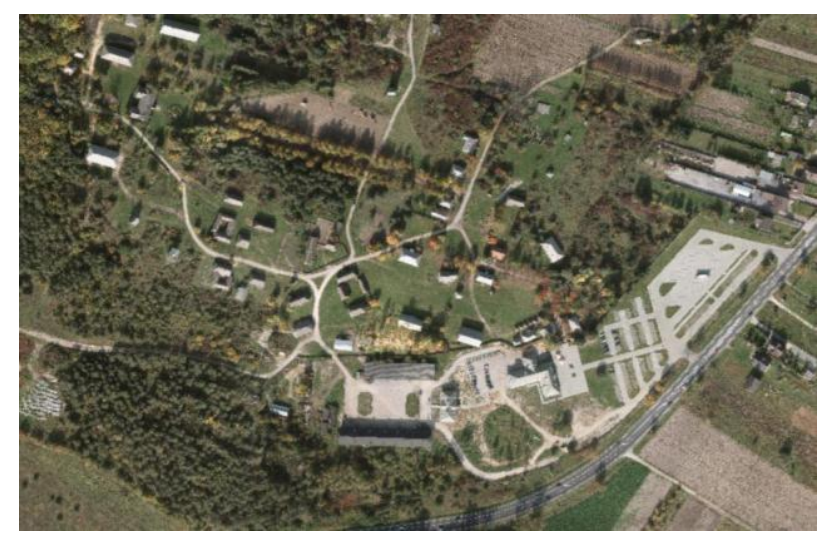

Figure 7. Orthophoto generated with $3 \mathrm{~cm}$ pixels.

\section{SELECTED EXPERIMENTS}

In images in Figs. 8 and 11 we can compare the difference as regards geometry and radiometry for both systems of photographs. We see that the buildings and roads are on the same level of details. At first glance we notice that the UAV technology could replace typical photogrammetry photographs.

\subsection{Radiometry of images}

Radiometry was checked by a visual method. After initial preprocessing of data (stretching their histograms), the images were put together and shown side by side in Fig. 8-11. The buildings and strips on the road were selected from whole data for comparison of edges and details.

In Fig. 10 we can see that in a classical photograph we recognize "pixel effect", which means that edges of lines are not so smooth, as in UAV images. It proves that UAV images can be more suitable for interpretation and for some automatic feature extraction procedures (results of those tests will be presented in separate papers).

In images 8-11 we see that the level of details is, however, similar for both images. To avoid errors generated by DTM and ortho, assessment was made on the aerial photographs (left classic - UAV right). For a better comparison images from UAV have been rotated to obtain a similar position of the building. A similar level of detail is visible especially in Figure 9, where the histograms are also shown to compare. Figure 10 and 11 show that classic photographs are more sharp, but it could be also the problem of JPEG compression used during the recording of the data. In general, it can be said that photographs from UAVs are not worse than classic ones. In my opinion, radiometric quality is at a similar level. 

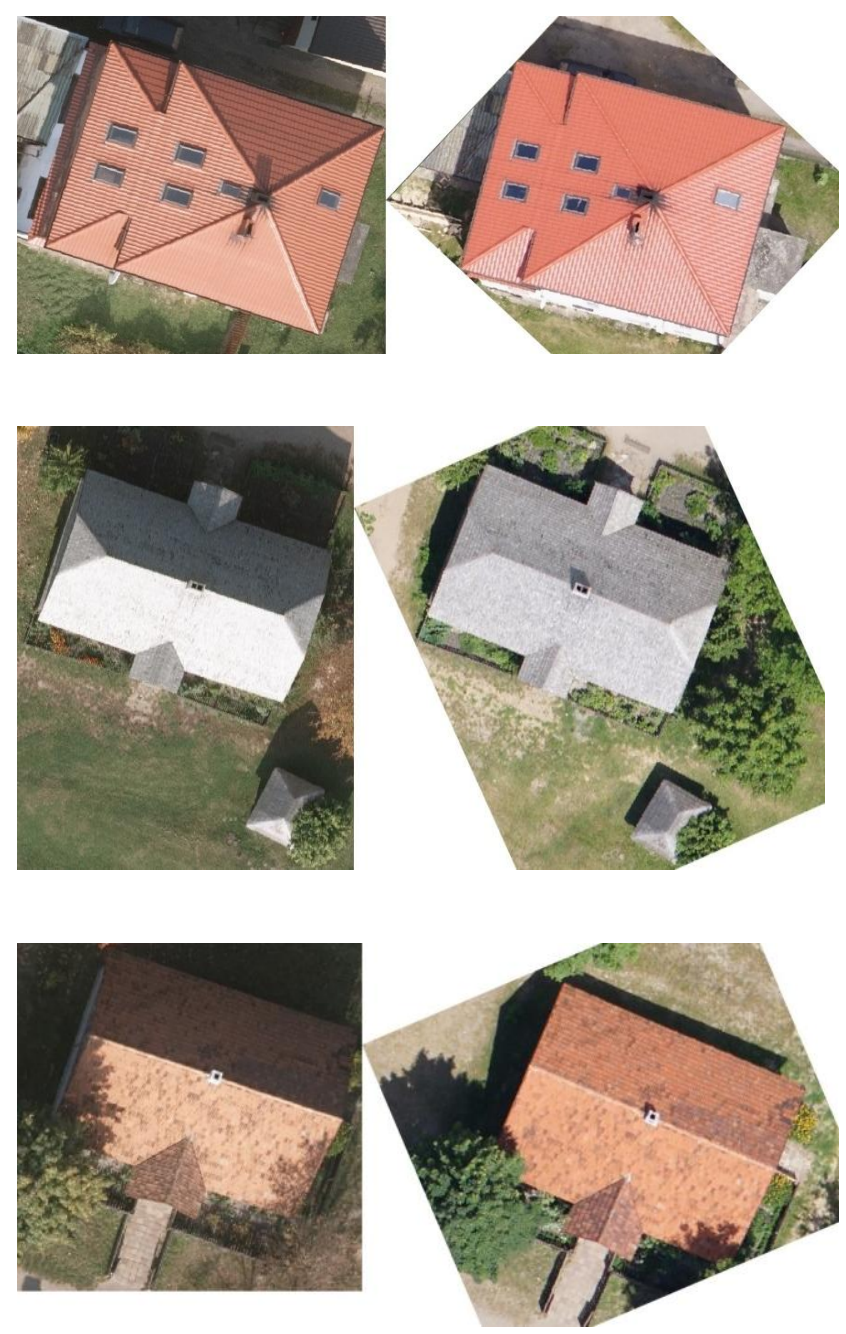

Figure 8. Comparison of images taken from the aircraft - classic (left) and UAV (right) for the same area - a selected building. Images from UAV have been rotated to obtain a similar position of the building.
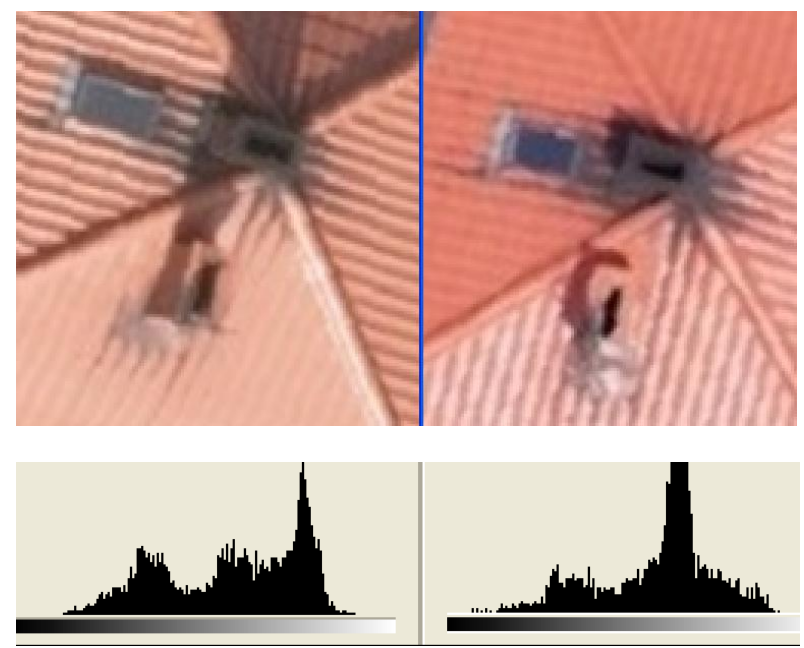

Figure 9. The part of one image - classic (left) and UAV (right) and their histograms
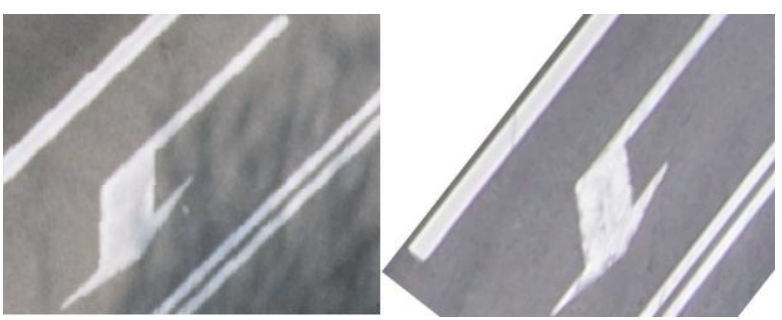

Figure 10. Comparison of images taken from the aircraft (left) and UAV (right) for the same area - a selected roads. Images from UAV have been rotated to obtain a similar position of the road.
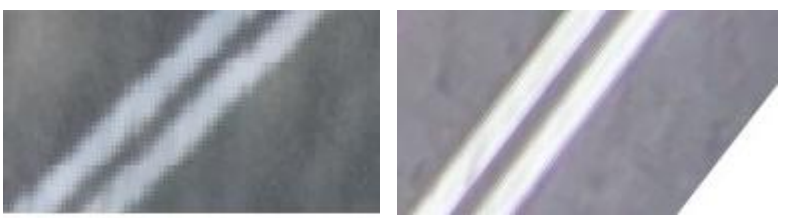

Figure 11. Zoom and comparison of images taken from the aircraft (left) and UAV (right) for the same area on the road

But on the other hand both images (figure 12) after use of Laplace'a filter looks similar at first glance, but on the left image we see wider edges than on the right image. Wider edges shows more noise in image. It is proof of above statement.
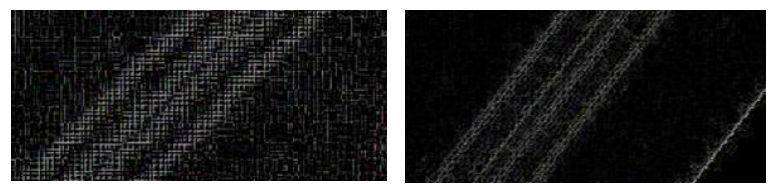

Figure 12. Images from Figure 8 after using Laplace'a filter

The big problem of UAV technology is that of the lack of coverage. During the flight due to high winds there may occur gaps in coverage, what can be shown on the orthophoto (Fig. 13).

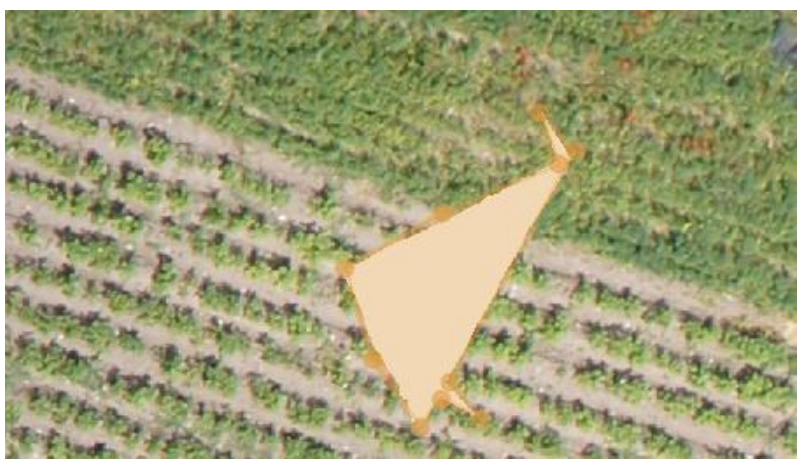

Figure 13. Lack in coverage on UAV orthophoto. 
This problem can be avoided by an appropriate increasing of photographs coverage, or carrying out a flight at a completely windless weather. However, one should be prepared for such "surprises" in case of windy weather.

\subsection{Geometry of images}

The geometry of images was checked under the process of aerotriangulation. In Figs. 7 one could see the GCP used for aerotriangulation.

To compare accuracy of these two flights, control and check points were used. RMSE were calculated according to the equation (1)

$$
R M S E_{w}=\sqrt{\frac{\Sigma v_{w}^{2}}{n-1}}
$$

where:

$\mathrm{v}_{\mathrm{w}}-$ deviation calculated between points on orthophoto and terrain

$\mathrm{n}$ - number of points.

For both projects the same GCP were used. In table 2 we can see the block adjustment results for classic data in table 3 from UAV.

The block adjustment was made with the use of AgiSoft software, which is one of the leaders on the UAV software market.

From those results we can see that the RMS on check points is on the level of $0.5-1$ pixels. It is a very good result for data taken from a non-metric camera (UAV technology).

\begin{tabular}{|c|c|c|}
\hline No & $\mathrm{dX}$ & $\mathrm{dY}$ \\
\hline & \multicolumn{2}{|c|}{ Control points } \\
\hline 1004 & 0.02 & 0.01 \\
\hline 1014 & 0.02 & 0.07 \\
\hline 1015 & 0.02 & 0.01 \\
\hline 2001 & 0.01 & -0.01 \\
\hline 2008 & 0.00 & 0.04 \\
\hline 2012 & -0.01 & -0.01 \\
\hline \multicolumn{3}{|c|}{ Check points } \\
\hline 1001 & -0.03 & -0.01 \\
\hline 1009 & -0.01 & 0.02 \\
\hline 1011 & 0.02 & 0.03 \\
\hline 1013 & 0.01 & 0.03 \\
\hline 2002 & 0.01 & 0.01 \\
\hline 2005 & 0.00 & -0.01 \\
\hline 2010 & -0.02 & 0.01 \\
\hline 2011 & -0.02 & -0.03 \\
\hline
\end{tabular}

Table 2. Deviation measured on orthomaps and in terrain by GPS technology, on selected points for the classical flight

The RMSE on control points was $\mathrm{m}_{\mathrm{x}}=0,030 \mathrm{~m}$ and $\mathrm{m}_{\mathrm{y}}=0,038$ $\mathrm{m}$, the RMSE on check points was $\mathrm{m}_{\mathrm{x}}=0,014$ and $\mathrm{m}_{\mathrm{y}}=0,031$ (table 2) for classic technology.

The RMSE on control points was $\mathrm{m}_{\mathrm{x}}=0,017 \mathrm{~m}$ and $\mathrm{m}_{\mathrm{y}}=0,022$ $\mathrm{m}$, the RMSE on check points was $\mathrm{m}_{\mathrm{x}}=0,019$ and $\mathrm{m}_{\mathrm{y}}=0,022$ $\mathrm{m}$ (table 4) - for UAV technology.
As you can see it is comparable accuracy on the level of 1 pixel $(3 \mathrm{~cm})$.

\begin{tabular}{|c|c|c|}
\hline No & $\mathrm{dX}$ & $\mathrm{dY}$ \\
\hline & \multicolumn{2}{|c|}{ Control points } \\
\hline 1004 & -0.02 & -0.02 \\
\hline 1014 & 0.02 & 0.04 \\
\hline 1015 & 0.00 & -0.02 \\
\hline 2001 & 0.03 & 0.06 \\
\hline 2008 & 0.02 & 0.03 \\
\hline 2012 & -0.05 & -0.02 \\
\hline \multicolumn{3}{|c|}{ Check points } \\
\hline 1001 & -0.02 & 0.05 \\
\hline 1009 & -0.04 & 0.03 \\
\hline 1011 & 0.02 & 0.02 \\
\hline 1013 & 0.04 & 0.03 \\
\hline 2002 & -0.02 & -0.03 \\
\hline 2005 & 0.05 & 0.01 \\
\hline 2010 & -0.01 & -0.02 \\
\hline 2011 & 0.05 & 0.03 \\
\hline
\end{tabular}

Table 3. Deviation measured on orthomaps and in terrain by GPS technology, on selected points for the UAV flight

\section{SUMMARY}

The objective of this paper was to demonstrate the author's experience in the UAV technology. The goal of the research was to answer the question: can UAV images replace typical photogrammetry images taken from aircrafts, where the related cost is much more higher?

The geometry and radiometry features were checked. In Figs. 9 and 12 one could see that the details on UAV images were not worse than those on classical photogrammetric images. One might suppose that geometrically they were also correct.

The results of aerotriangulation prove these facts, too. Final results from aerotriangulation were on the level of RMS $=1$ pixels (about $3 \mathrm{~cm}$ ). This is a very significant result as regards mapping.

It means that UAV data can be used in mapping production, although the use of classic non-metric cameras may sometimes be replaced with cameras of continuous recording.

A future-oriented development tendency is the installation of laser scanners and hyperspectral sensors (e.g. Rikola Hyperspectral UAV camera can record 50 spectral channels within 500-950 $\mathrm{nm}$ range). UAVs are implemented in various projects in the fields of typical photogrammetry (mapping), teledetection, or the so-called precise agriculture.

Today, we can confidently declare that part of that has been achieved. The already emerging first products of that technology implementation are successfully utilized in selected projects.

\section{ACKNOWLEDGEMENTS}

This work was financed by research grants: 15.11.150.129/14. Special thanks to companies MGGP AERO Ltd. from Tarnow and FlyTech Ltd. from Cracow for providing software and equipment for testing. 


\section{REFERENCES}

Eisenbeiss H., 2004. A mini Unmanned Aerial Vehicle (UAV): system overview and image acquisition. International Archives of Photogrammetry, Remote Sensing and Spatial Information Sciences, vol. XXXVI, part 5/W1 (CD-ROM).

Sawicki, P., 2012. Unmanned UAVs in photogrammetry and remote sensing - current status and development trends. Archives of Photogrammetry, Cartography and Remote Sensing. Vol. 23, pp. 365-376.

Szczechowski, B., 2008. The use of UAVs (mini helicopters) for making photogrammetric aerial photos from low ceilings. Archives of Photogrammetry, Cartography and Remote Sensing, Vol.18., pp. 569-579.

Mikrut, S., Głowienka-Mikrut, E., Michałowska, K., 2013. The UAV technique as a future direction of development of lowceiling aerial photogrammetry. Geomatics and Environmental Engineering, Vol.7, no 4., pp. 69-77. 